\title{
Does bonding to Dentin reduce Gap formation in Composite Restorations?
}

Daniela Araújo Veloso Popoff, Murilo de Sousa Menezes, Andressa dos Santos Gomes, André Luis Faria-e-Silva, Paulo Vinícius Soares, Paulo César Santos-Filho, Luís Roberto Marcondes Martins

\begin{abstract}
This study evaluated the effect of adhesive application only to enamel on the gap formation of composite resin restorations performed with different adhesive systems and submitted to mechanical cycling. Standardized cylinder-shaped cavities were prepared on the buccal surface of 60 bovine incisors. Two etchand-rinse [Adper S cotchbond Multi-purpose (3M ESPE, St. Paul, MN, USA) and Adper Single Bond 2 (3M ESPE)] and one selfetching [Clearfil SE Bond (Kuraray, Osaka, Japan)] adhesive systems were evaluated. The adhesives were applied only to enamel or to both dentin and enamel. After adhesive light activation, the cavities were restored with composite resin. The restorations were finished and polished; the marginal adaptation was analyzed using scanning electronic microscopy (SEM, 500x magnification) in low-vacuum mode. After the first evaluation, the samples were submitted to mechanical cycling $(300,000$ cycles of $80 \mathrm{kN}$ and $1.5 \mathrm{~Hz}$ ) and a new evaluation was performed. There was observed any gap for all experimental conditions before and after mechanical cycling. Bonding to dentin does not alter the marginal adaptation of composite restorations.
\end{abstract}

Keywords: Adhesives, Composite resins, Dental bonding, Dental restoration failure.

How to cite this article: Popoff DAV, Menezes MS, Gomes AS, F aria-e-Silva AL, S oares PV, Santos-Filho P C, Martins LR M. Does bonding to Dentin reduce Gap formation in Composite Restorations? Int J Experiment Dent Sci 2012;1(2):67-70.

Source of support $\mathrm{Nil}$

Conflict of interest: None

\section{INTRODUCTION}

Despite the improvements of restorative material in recent decades, the marginal integrity of restoration remains a challengefor dentistry. Poor marginal adaptation may produce marginal discoloration, postoperative sensibility and secondary caries. ${ }^{1}$ These are the most frequent reasons to replace or repair an adhesive restoration. ${ }^{2}$ The marginal failure of composite resin restorations is mainly related the restorative technique, resin composite and adhesive system used. ${ }^{3}$

Debonding followed by gap formation can be observed when the restoration is submitted to stresses. If stress exceeds the bond strength between the dental substrate and the adhesive system, a contraction gap will be formed, jeopardizing the restoration's longevity. ${ }^{4}$ The stress can be caused by polymerization shrinkage or resin composite, occlusal loads and/or alterations of temperature of oral behavior. ${ }^{5,6}$ M oreover, the gap formation can be also affected by location of restoration margins. ${ }^{7}$
M ost studies of adhesive systems have demonstrated that the bond of adhesive to enamel is predictable. ${ }^{8,9}$ However, the bond procedure to dentin is more complex, resulting in more failures. ${ }^{10} \mathrm{Clinically,} \mathrm{keeping} \mathrm{the} \mathrm{margins}$ sealed is the main factor in the clinical success of adhesive restorations. ${ }^{11,12}$ Considering that the majority of restorations have all margins at the enamel, bonding the composite only to enamel may, theoretically, be sufficient to maintain the proper marginal seal.

Thus, the aim of this study was to eval uate the effect of adhesive application only to enamel on gap formation in cavities of class $V$, with a margin at the enamel, submitted to mechanical cycling. The null hypothesis was that bonding to dentin and mechanical cycling does not alters gap formation of composite restorations, presenting all margins at enamel.

\section{MATERIALS AND METHODS}

One week after extraction, sound bovine incisors were cleaned, polished and examined under a light microscope (Eclipse E 600; Nikon, Shinagawa-ku, Tokyo, Japan) in order to exclude those with cracks. Sixty teeth were selected and stored in distilled water at $5^{\circ} \mathrm{C}$ for less than 1 month before the restorative procedure. The buccal surface was slightly wet-ground with 1200-grit SiC abrasive paper to obtain a flat area in enamel. A fterwards, a circular-shaped class $V$ cavity $(2.0 \pm 0.05 \mathrm{~mm}$ diameter by $2.0 \mathrm{~mm}$ depth) was prepared on the central part of the block using a \#4054 diamond bur (K G Sorensen Ind. Com. L tda., Barueri, SP, $B$ razil). The cavities were performed to $4 \mathrm{~mm}$ from enamelcement junction using a water-cooled high-speed turbine attached to a standard cavity preparation device. A new bur was used for each of the five preparations.

Cavities were randomly assigned into six groups according to a combination of the adhesive system and application mode. The adhesive systems used in this study and respective application descriptions are summarized in Table 1. The application was performed only to enamel or to all cavity walls (both enamel and dentin). When the adhesive was applied only to enamel, all adhesive procedures was performed under an optical microscope (30x, EM Z-TR, M eiji Techno Co., Saitama, Japan) and using an extrafine microbrush (Cavibrush, FGM , Joinville, SC, Brazil). 
Daniela Araújo Veloso Popoff et al

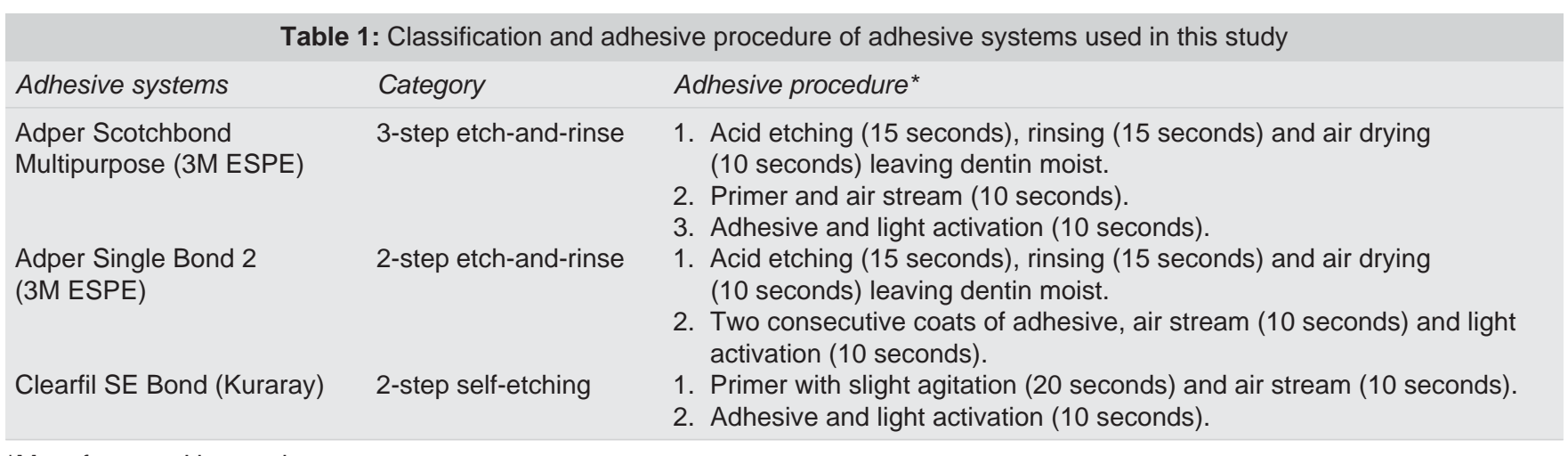

*Manufacturers' instructions

The cavities were restored with a microhybrid resin composite (Filtek Z-250, 3M ESPE, St. Paul, M N, USA), filled in one (bulk) increment of $2 \mathrm{~mm}$ and light-activated for 20 seconds. A light-curing unit O ptilux 501 (Demetron K err, Danbury, USA ) with an output intensity of $650 \mathrm{~mW} / \mathrm{cm}^{2}$ was used in this study. The output of the light-curing unit was periodically checked using a handheld radiometer (Model 100, Demetron Kerr). A fter restoration, all specimens were stored in distilled water at $37^{\circ} \mathrm{C}$ for 24 hours and polished with flexible aluminum oxide disks (Sof-L ex Pop-on ${ }^{\circledR}, 3 M$ ESPE, St. Paul, MN, USA) under a water spray. A ll specimens were kept in water at $37^{\circ} \mathrm{C}$ for 24 hours.

The specimens were allowed to desiccate in covered unseal ed plastic containers for 48 hours at room temperature in a dust-free environment. This time was sufficient to allow complete drying of the specimen. Specimens were examined using a scanning electron microscopy (SEM ; J SM -5600L V , JEOL, Tokyo, Japan), which is capable of both low vacuum (LV) and high vacuum (HV) operations. The analyses were performed under LV condition at $25 \mathrm{kV}$ and 0.3 Torr. All extension of restoration margins were analyzed under $500 \mathrm{X}$ of magnification. A fter the first evaluation, samples were submitted to the mechanical load in a cyclic mechanical loading device (E rios R epresentações e Comércio L tda, São Paulo, B razil). Specimens were submitted to 300,000 cycles with a vertical load of $80 \mathrm{kN}$ and a frequency of $1.5 \mathrm{~Hz}$. The samples remained in distillated water at $37^{\circ} \mathrm{C}$ during the mechanical cycling. Afterwards, restorations margins were evaluated again.

\section{RESULTS}

No gap was observed for all experimental conditions at two moments of evaluation. Figures $1 A$ and $B$ illustrates the evaluations of restorations margins.

\section{DISCUSSION}

A proper margin sealing is essential to improve the longevity of resin composite restorations. Clinical evaluations of restorations are very complicated because of ethical reasons,
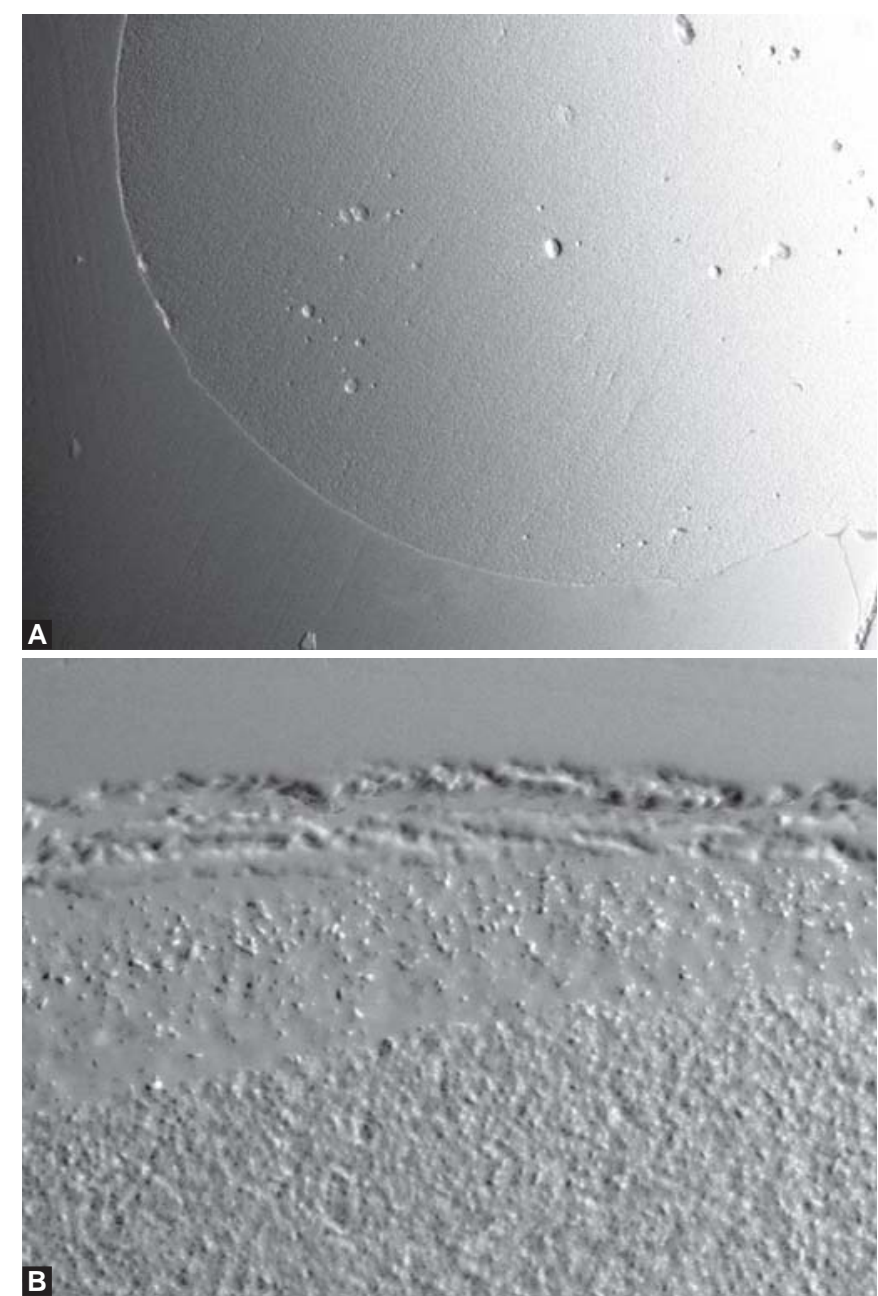

Figs 1A and B: Representative microscopy of gap evaluation. (A) Low magnification image showing half of restoration (B) high magnification image used to evaluate the presence of gaps. Note: The absence of marginal gaps

and they are time-consuming and expensive. Invitrostudies simulating oral conditions have been performed in order to permit estimation of restoration longevity. Class $V$ cavities were chosen in this study because of their factor of cavity configuration that impairs the resin composite flowing during the polymerization shrinkage. ${ }^{13,14}$ In the present study, there was no observed gap in restorations margins even after the mechanical cycling. Thus, the null hypotheses were rejected. 
Does bonding to Dentin reduce Gap formation in Composite Restorations?

In composite restorations, gap formation is often related to polymerization shrinkage that causes tensile stress between the cavity wall and the restoration. ${ }^{3}$ This stress can disrupt the bond and lead to the formation of gaps. Thus, a proper bond of an adhesive to dental tissue contributes to avoid gap formation. ${ }^{15}$ The current study used bovine teeth as the bonding substrate to evaluate the microleakage of adhesive restorations. Reis et al ${ }^{16}$ analyzed bond strength and enamel and dentine morphology as possible substitutes for human teeth in bonding tests. The values of bond strengths obtained with bovine and human teeth are similar for either enamel or dentine. In addition, the morphology presented by these two substrates was also similar. Thus, it is expected that the performance of adhesives would not be compromised by the use of bovine teeth and that the outcomes are expected to be similar for human teeth.

It has been demonstrated that all adhesives systems used in this study present proper bonding to both enamel and dentin. ${ }^{9}$ The outcomes of this study showed that only the proper bonding to enamel is enough to avoid the gap formation. A dditionally to fact that the bonding to enamel seals the restoration margins, the adhesive application only to enamel reduces the bonding area of restoration, resulting in lower $\mathrm{C}$-factor. ${ }^{17}$ Thus, it can expect a lower stress of polymerization on this situation, favoring the maintenance of marginal sealing.

The main aim of a dental restoration is to create an adequate seal, preventing the microleakage of contaminants contained in the oral environment. The outcomes of this study show that proper bonding to enamel seems to be sufficient to obtain marginal integrity and to avoid gap formation. The utilization of these adhesives on dentin did not alter the gap formation. However, it is important to emphasize that the restorations used in this study were submitted only to mechanical cycling. Considering that thermal cycling can also cause stress in dental restorations, further studies are necessary before definite conclusions can be made in determining whether similar findings will be found elsewhere.

\section{REFERENCES}

1. Heintze SD. Systematic reviews: I. The correlation between laboratory tests on marginal quality and bond strength. II. The correlation between marginal quality and clinical outcome. J A dhes Dent 2007;9:77-106.

2. Popoff D, Rosa TS, Ferreira R, M agal hães $C$, M oreira A, M jör IA. R epair of dimethacrylate-based composite restorations by a silorane-based composite: A one-year randomized clinical trial. Oper Dent 2012 Sep-Oct;37(5):E1-E10.

3. V an Ende A, De M unck J, M ine A, L ambrechts $P, V$ an M eerbeek $B$. Does a low-shrinking composite induce less stress at the adhesive interface? Dent M ater 2010;26:215-22.
4. Takahashi $H$, Finger WJ, W egner $K$, U tterodt $A$, Komatsu $M$, Wöstrmann $B$, et al. Factors influencing marginal cavity adaptation of nanofiller containing resin composite restorations. Dent $M$ ater 2010;26:1166-75.

5. W ang Y, L iao Z, Liu D, Liu Z, M clntyre GT, Jian F, et al. 3DFEA of stress levels and distributions for different bases under a Class I composite restoration. A m J Dent 2011;24:3-7.

6. Hashemipour M A, M ohammadpour A, Nassab SA. Transient thermal and stress analysis of maxillary second premolar tooth using an exact three-dimensional model. Indian J Dent Res 2010;2:158-64.

7. Garcia-Godoy F, K rämer N, F eilzer A J , Frankenberger R . L ongterm degradation of enamel and dentin bonds: Six-year results in vitro vs in vivo. Dent M ater 2010 Nov;26(11):1113-18.

8. M arshall SJ , B ayne SC, B aier R, T omsia A P, M arshall GW . A review of adhesion science. Dent $M$ ater 2010;26:11-16.

9. De M unck J, V an Landuyt K, Peumans $M$, Poitevin A, Lambrechts $P, B$ raem $M$, et al. A critical review of the durability of adhesion to tooth tissue: Methods and results. J Dent Res 2005;84:118-32.

10. B reschi L, M azzoni A, Ruggeri A , C ardenaro M , Di L enarda R, De Stefano Dorigo E. Dental adhesion review: A ging and stability of the bonded interface. D ent M ater 2008;24:90-101.

11. K ancaJ 3rd, Greitzer G. Class II restorations with margins below the CEJ. J Esthet Restor Dent 2009;21:193-201.

12. Shook LW, Turner EW, Ross J, Scarbecz M. Effect of surface roughness of cavity preparations on the microleakage of class $\mathrm{V}$ resin composite restorations. Oper D ent 2003;28:779-85.

13. Franco $E B, B$ enetti $A R$, Ishikiriama $S K$, Santiago $S L$, L auris $J R$, Jorge $M F$, et al. 5-year clinical performance of resin composite versus resin modified glass ionomer restorative system in non-carious cervical lesions. Oper Dent 2006;31: 403-08.

14. Santiago SL, Passos VF, V ieira A H, Navarro M F, L auris JR, Franco EB. Two-year clinical performance of resinous restorative system in non-carious cervical lesions. Braz Dent J 2010;21:229-34.

15. K hosravi K, A taei E, M ousavi M, K hodaeian N. Effect of phosphoric acid etching of enamel margins on the microleakage of a simplified all-in-one and a self-etch adhesive system. O per Dent 2009;34:531-36.

16. Reis AF, Giannini M, Kavaguchi A, Soares CJ, Line SR. Comparison of microtensile bond strength to enamel and dentin of human, bovine, and porcine teeth. J A dhes Dent 2004;6: 117-21.

17. Vaidyanathan TK, V aidyanathan J. Recent advances in the theory and mechanism of adhesive resin bonding to dentin: $A$ critical review. J Biomed $M$ ater Res B Appl Biomater 2009;88:558-78.

\section{ABOUT THE AUTHORS}

\section{Daniela Araújo Veloso Popoff}

Professor, D epartment of D entistry, State U niversity of M ontes Claros M inas Gerais, B razil

Correspondence Address: Rua Porto Seguro, 1100/367, B airro Ibituruna, cep: 39401-290, M ontes Claros, M inas Gerais, B razil Phone: 55-38-99859911, e-mail: danielavelloso@yahoo.com.br 


\section{Murilo de Sousa Menezes}

Professor, Department of Operative Dentistry and Dental M aterials Federal University of U berlândia, M inas Gerais, B razil

\section{Andressa dos Santos Gomes}

Undergraduate Student, D epartment of Piracicaba D ental School, State University of Campinas, São Paulo, B razil

\section{André Luis Faria-e-Silva}

Professor, Department of Dentistry, Federal University of Sergipe Sergipe, B razil

\section{Paulo Vinícius Soares}

Professor, Department of Operative Dentistry and Dental M aterials Federal U niversity of U berlândia, M inas Gerais, B razil

\section{Paulo César Santos-Filho}

Professor, Department of Operative Dentistry and Dental Materials Federal U niversity of U berlândia, M inas Gerais, A merican Samoa

\section{Luís Roberto Marcondes Martins}

Professor, Department of Piracicaba D ental School, State U niversity of Campinas, São Paulo, B razil 